\title{
Real-world outcomes in patients with unresected stage III non-small cell lung cancer
}

\author{
Kellie J. Ryan ${ }^{1} \cdot$ Karen E. Skinner $^{2} \cdot$ Ancilla W. Fernandes $^{1} \cdot$ Rajeshwari S. Punekar $^{2,4} \cdot$ Melissa Pavilack $^{1}$. \\ Mark S. Walker ${ }^{2} \cdot$ Noam A. VanderWalde ${ }^{3}$
}

Received: 18 December 2018 / Accepted: 21 January 2019 / Published online: 31 January 2019

(c) The Author(s) 2019

\begin{abstract}
This study examined real-world clinical outcomes such as progression-free survival (PFS), time to metastasis (TTM), overall survival (OS), and health-related quality of life (HRQOL) in patients with unresected stage III non-small cell lung cancer (NSCLC) treated in the community setting. A retrospective review of medical records extracted from 10 US community oncology practices was conducted. Eligible patients were adults diagnosed with stage III NSCLC from 1/1/2011 to 3/1/2016 without evidence of surgical resection within 6 months after stage III NSCLC diagnosis (index date). PFS, OS, and TTM were assessed from the index date, and were analyzed using Kaplan-Meier and Cox regression analyses. HRQOL was assessed for a subset of patients using a patient-reported measure, the 86-item Patient Care Monitor (PCM). Linear mixed models (LMM) were used to assess the impact of patient characteristics and change in PCM scores associated with progression. Among the sample of 478 patients, median PFS (95\% confidence interval) was 10 months (9-11), median OS was 20 months (17-22), and median TTM was 30 months (23-45). Most patients (58.2\%) experienced disease progression, which the LMM showed to be associated with significant worsening of physical symptoms and psychological states $(p<0.001)$. This study documented PFS and OS consistent with published literature. The majority of patients experienced disease progression, which was associated with worsening of HRQOL. These findings highlighted the need for better therapeutic options in patients with unresected stage III NSCLC with potential to improve patient outcomes and HRQOL.
\end{abstract}

Keywords Treatment patterns $\cdot$ Progression-free survival $\cdot$ Overall survival $\cdot$ Health-related quality of life $\cdot$ Community oncology

Previous publication: A portion of this research was presented at the Academy of Managed Care Pharmacy Managed Care \& Specialty Pharmacy Annual Meeting, April 23-26, 2018.

Karen E. Skinner

kskinner@vectoroncology.com

Kellie J. Ryan

Kellie.Ryan@astrazeneca.com

Ancilla W. Fernandes

Ancilla.Fernandes@astrazeneca.com

Rajeshwari S. Punekar

raju.punekar@gmail.com

Melissa Pavilack

Melissa.Pavilack@astrazeneca.com

Mark S. Walker

mwalker@vectoroncology.com

\section{Introduction}

Lung cancer is the leading cause of cancer-related deaths in men and women in the United States, with an estimated 158,770 deaths in 2018 [1]. Approximately, $80-85 \%$ of

Noam A. VanderWalde

nvanderw@westclinic.com

1 AstraZeneca, One MedImmune Way, Gaithersburg, MD 20878, USA

2 Vector Oncology, 6555 Quince, Suite 400, Memphis, TN 38119, USA

3 West Cancer Center, 7945 Wolf River Boulevard, Germantown, TN 38138, USA

4 Present Address: Sanofi, 50 Binney Street, 2nd floor, Cambridge, MA 02142, USA 
patients with lung cancer present with non-small cell lung cancer (NSCLC) [2]. About 25\% of patients first diagnosed with NSCLC are diagnosed with stage III disease, which in most cases is unresectable [3]. In the 8th and most recent American Joint Committee on Cancer (AJCC) staging system published in 2017, stage III disease includes stage IIIA, stage IIIB, and also stage IIIC. The 5-year survival rate for stage IIIA is $36 \%$, for stage IIIB is $26 \%$, and for stage IIIC is $13 \%$ [4]. Stage IIIC is a newly defined group, which now includes patients with $\mathrm{T} 3$ or $\mathrm{T} 4$ disease, and N3 disease [5, 6]. In the older staging system, patients who are now classified as stage IIIC would have been considered stage IIIB.

For patients with good performance status who have inoperable stage III disease, treatment guidelines recommend treatment with platinum-based doublet chemotherapy concurrent with radiation $[7,8]$. The combined modality therapy of chemoradiation (CRT) has been shown to be superior to radiation therapy alone for patients with unresectable stage III NSCLC [9].

Until recently, there have been no major improvements in therapy options for patients with unresectable stage III NSCLC outside of optimization of chemoradiation regimens. This has changed with the US Food and Drug Administration's approval of durvalumab in the treatment of unresectable stage III NSCLC in patients whose disease has not progressed following concurrent platinum-based chemotherapy and radiation therapy [10]. However, there is limited information available on treatment patterns and burden of disease for the stage III NSCLC population prior to the approval of durvalumab. This is especially true for stage III NSCLC patients who are treated in the community setting. To fill this gap, this retrospective study examined treatment patterns and effectiveness outcomes as well as health-related quality of life (HRQOL) in patients with unresected stage IIIA and IIIB NSCLC treated in the community setting.

\section{Materials and methods}

\section{Study design}

This was a retrospective, observational study using data from the Vector Oncology Data Warehouse, a repository of structured and unstructured electronic medical record (EMR) data from a geographically diverse set of ten community oncology practices in the United States. Data utilized in this study included patient characteristics, treatment patterns, effectiveness outcomes, and HRQOL. Provider notes supported the collection of key information not otherwise available in structured data fields (e.g., performance status, confirmation of and dates for disease progressions, comorbidities) through review of the EMR by experienced Clinical Research Nurses.

The study index date was defined as the date of stage III NSCLC diagnosis, occurring between January 2011 and March 2016. Data collection for each patient included the period from the index date through the end of the third progression interval. A progression interval was defined as the period between disease progression events. The first progression interval was defined as the period between the index date and the first disease progression (described later), and subsequent progression intervals were defined as the period between sequential disease progressions (Fig. 1). The study did not require treatment, such as systemic anti-cancer therapy or radiation therapy, during these progression intervals (Fig. 1). The protocol for this study received institutional review board (IRB) approval from IntegReview (Austin, $\mathrm{TX})$.

\section{Patients}

Eligible patients met the following criteria: (1) Adults ( $\geq 18$ years old) diagnosed with stage III NSCLC (ICD-9
Fig. 1 Examples of treatment pattern and flow chart for definition of lines of treatment. $N S C L C$ non-small cell lung cancer

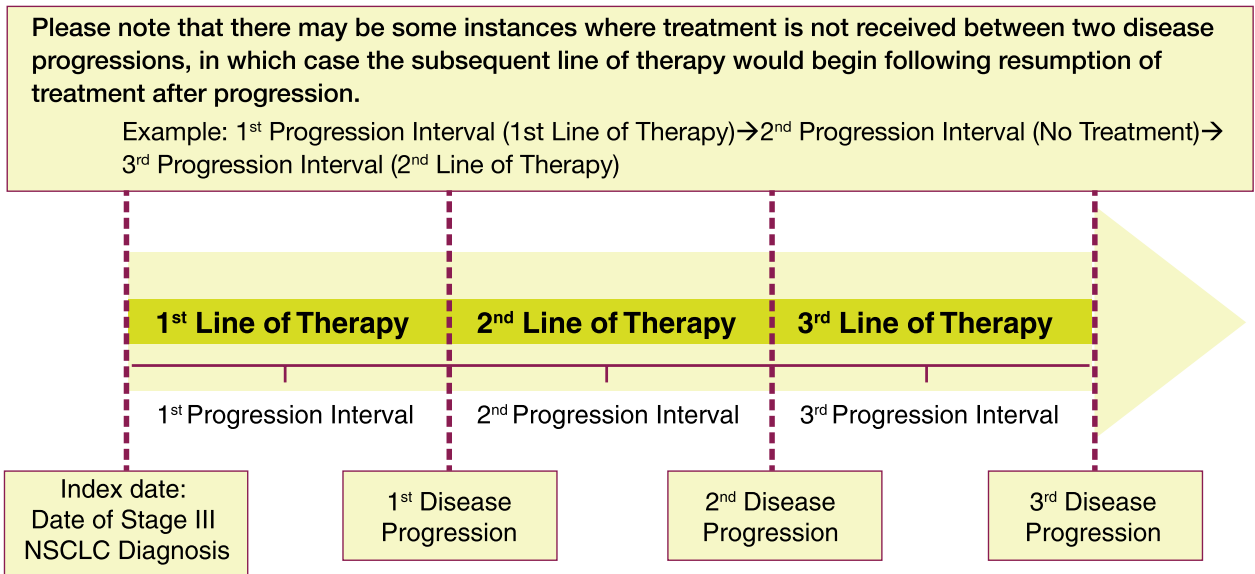


code of 162.x or ICD-10 code of C33.x or C34.x) between January 2011 and March 2016 and (2) no evidence of surgical resection within 6 months following stage III NSCLC diagnosis. Patients participating in anti-cancer clinical trials during the observation period, and those who received a diagnosis of, or treatment for, another primary cancer were excluded from the study.

\section{Study outcomes}

The outcomes of interest in this study were progressionfree survival (PFS), overall survival (OS), and time to metastatic disease (TTM). PFS was assessed for each progression interval. PFS for the first progression interval was measured from the index date (stage III NSCLC diagnosis) until occurrence of disease progression, or death, whichever occurred first. PFS for the subsequent progression intervals was assessed from the previous disease progression until the occurrence of the subsequent disease progression, or death, whichever occurred first. The occurrence and date of disease progression were determined from documentation within the patient record, such as pathology reports, imaging report notes, and statements about disease progression in the oncologist progress notes. OS was defined as the interval from the index date until death. Dates of death were determined from the medical record and the Social Security Death Index. TTM was defined as the time between the index date and diagnosis of metastatic disease, as documented in the oncologist progress notes within the patient medical record. Patients who died prior to metastatic diagnosis were censored to focus the analysis on understanding TTM separate from OS. The TTM analysis evaluated the expected timing of TTM events for patients who remained alive.

The study also examined HRQOL as measured by the Patient Care Monitor 2.0 (PCM 2.0). PCM 2.0 is an 86-item self-report measure that is administered as part of routine care to assess physical symptoms, psychological symptoms, and physical functioning. Patients are asked to rate the severity of symptoms on an 11 point ( 0 to 10 ) Likert-type scale, where higher scores reflect more severe symptoms [11-17]. The validity of the PCM for assessing symptom burden and HRQOL in cancer patients has been demonstrated in numerous studies [12, 13, 17-19]. The PCM 2.0 provides summary Index Scores for: General Physical Symptoms, Treatment Side Effects, Acute Distress, Despair, Impaired Ambulation, and Impaired Performance. In this study, specific PCM symptom-based items of importance were selected for analysis according to relevance to advanced NSCLC (diarrhea, nausea, pain, difficulty breathing, coughing, fatigue, and weight loss).

\section{Statistical analysis}

The study sample was stratified by stage (stage IIIA, stage IIIB, stage III not specified) and by histology (Squamous Cell Carcinoma, Adenocarcinoma, Other). Note that the study period predates the changes in NSCLC staging to include stage IIIC disease [5]. Descriptive methods were used to evaluate patient characteristics for the overall sample. Fisher's Exact test or Chi square, and t test or Wilcoxon rank sum test were used to compare patient characteristics by patient groups on categorical and continuous variables, respectively. Comparative analyses were conducted between the stage IIIA and stage IIIB groups, and separately between the Squamous Cell Carcinoma and Adenocarcinoma groups.

Unadjusted PFS, OS, and TTM were analyzed using Kaplan-Meier methods with a log rank test. Multivariate Cox regression models were used to examine the impact of stage-based grouping and histology-based grouping on PFS, OS, and TTM while controlling for demographic and clinical covariates. Linear mixed models (LMM) were used to examine PCM Index Scores and PCM items over progression intervals. These models included change over time within the respective interval and the impact of disease progression. They also examined effects of stage-based groups, histologybased groups, and presence vs. absence of radiation therapy.

\section{Results}

\section{Demographic and clinical characteristics}

The study sample included 478 patients, of which $52.1 \%$ were stage IIIA, 38.9\% were stage IIIB, and $9.0 \%$ were stage III unspecified at the time of stage III diagnosis (Table 1). The overall mean age of patients was 67.2 years (SD 10.2), $44.8 \%$ were female, and $72.4 \%$ were Caucasian. Consistent with the broader Vector Oncology Data Warehouse, most patients (83.7\%) were from the Southern region of the U.S. Less than $15 \%$ of the total sample had impaired performance status (13.8\%) as defined by Eastern Cooperative Oncology Group (ECOG) $\geq 2$ or other text reference to impairment in the patient record. The majority of patients were either current smokers (46.2\%) or past smokers (50.0\%), with less than $4 \%$ having never smoked. Relatively few patients received biomarker testing during the period of observation (index date through the end of the third progression interval), with testing rates of epidermal growth factor receptor (EGFR): $33.5 \%$, anaplastic lymphoma kinase (ALK): $30.3 \%$, Kirsten rat sarcoma viral oncogene homolog (KRAS): $14.2 \%$, programmed cell death-1 (PD-1): $4.8 \%$, or programmed deathligand-1 (PD-L1): 8.6\%. Among those tested, the proportion of patients who were positive for each mutation was EGFR: 
Table 1 Demographic and clinical characteristics by stage-based groups

\begin{tabular}{|c|c|c|c|c|}
\hline \multirow[t]{2}{*}{ Variables } & \multicolumn{4}{|l|}{ Stage-based groups } \\
\hline & Stage IIIA $N=249$ & Stage IIIB $N=186$ & $\begin{array}{l}\text { Stage III (not speci- } \\
\text { fied) } N=43\end{array}$ & Overall $N=478$ \\
\hline Age, years, mean (SD) & $68.0( \pm 9.8)$ & $65.5( \pm 10.7)$ & $68.8( \pm 9.7)$ & $67.2( \pm 10.2)$ \\
\hline Female, $n(\%)$ & $119(47.8 \%)$ & $77(41.4 \%)$ & $18(41.9 \%)$ & $214(44.8 \%)$ \\
\hline \multicolumn{5}{|l|}{ Race, $n(\%)$} \\
\hline Caucasian & $184(73.9 \%)$ & $129(69.4 \%)$ & $33(76.7 \%)$ & $346(72.4 \%)$ \\
\hline Minority/unknown & $65(26.1 \%)$ & $57(30.6 \%)$ & $10(23.3 \%)$ & $132(27.6 \%)$ \\
\hline BMI, mean (SD) & $26.7( \pm 5.52)$ & $25.9( \pm 5.81)$ & $27.2( \pm 5.49)$ & $26.4( \pm 5.64)$ \\
\hline \multicolumn{5}{|l|}{ Region, $n(\%)$} \\
\hline Midwest & $49(19.7 \%)$ & $20(10.8 \%)$ & $7(16.3 \%)$ & $76(15.9 \%)$ \\
\hline Northeast & 0 & $2(1.1 \%)$ & 0 & $2(<1 \%)$ \\
\hline South & $200(80.3 \%)$ & $164(88.2 \%)$ & $36(83.7 \%)$ & $400(83.7 \%)$ \\
\hline \multicolumn{5}{|c|}{ Histology at initial NSCLC diagnosis, $n(\%)$} \\
\hline Adenocarcinoma & $103(41.4 \%)$ & $83(44.6 \%)$ & $17(39.5 \%)$ & $203(42.5 \%)$ \\
\hline Squamous cell carcinoma & $120(48.2 \%)$ & $83(44.6 \%)$ & $24(55.8 \%)$ & $227(47.5 \%)$ \\
\hline Other & $26(10.4 \%)$ & $20(10.8 \%)$ & $2(4.7 \%)$ & $48(10.0 \%)$ \\
\hline Impaired performance status, $n(\%)$ & $33(13.3 \%)$ & $27(14.5 \%)$ & $6(14.0 \%)$ & $66(13.8 \%)$ \\
\hline \multicolumn{5}{|l|}{ Smoking status, $n(\%)$} \\
\hline Current & $109(43.8 \%)$ & $94(50.5 \%)$ & $18(41.9 \%)$ & $221(46.2 \%)$ \\
\hline Never & $7(2.8 \%)$ & $9(4.8 \%)$ & $1(2.3 \%)$ & $17(3.6 \%)$ \\
\hline Past & $133(53.4 \%)$ & $83(44.6 \%)$ & $23(53.5 \%)$ & $239(50.0 \%)$ \\
\hline Not documented & 0 & 0 & $1(2.3 \%)$ & $1(<1 \%)$ \\
\hline \multicolumn{5}{|l|}{ EGFR mutation status, $n(\%)$} \\
\hline Tested for EGFR & $74(29.7 \%)$ & $73(39.2 \%)$ & $13(30.2 \%)$ & $160(33.5 \%)$ \\
\hline Positive & $6(8.1 \%)$ & $7(9.6 \%)$ & $3(23.1 \%)$ & $16(10.0 \%)$ \\
\hline \multicolumn{5}{|l|}{ ALK mutation status, $n(\%)$} \\
\hline Tested for ALK & $69(27.7 \%)$ & $65(34.9 \%)$ & $11(25.6 \%)$ & $145(30.3 \%)$ \\
\hline Positive & $1(1.4 \%)$ & $3(4.6 \%)$ & 0 & $4(2.8 \%)$ \\
\hline \multicolumn{5}{|l|}{ KRAS mutation status, $n(\%)$} \\
\hline Tested for KRAS & $28(11.2 \%)$ & $36(19.4 \%)$ & $4(9.3 \%)$ & $68(14.2 \%)$ \\
\hline Positive & $10(35.7 \%)$ & $5(13.9 \%)$ & 0 & $15(22.1 \%)$ \\
\hline \multicolumn{5}{|l|}{ PD- 1 expression status, $n(\%)$} \\
\hline Tested for PD-1 & $8(3.2 \%)$ & $15(8.1 \%)$ & 0 & $23(4.8 \%)$ \\
\hline Positive & $4(50.0 \%)$ & $8(53.3 \%)$ & 0 & $12(52.2 \%)$ \\
\hline \multicolumn{5}{|l|}{ PD-L1 expression status, $n(\%)$} \\
\hline Tested for PD-L1 & $16(6.4 \%)$ & $24(12.9 \%)$ & $1(2.3 \%)$ & $41(8.6 \%)$ \\
\hline Positive & $7(43.8 \%)$ & $3(12.5 \%)$ & 0 & $10(24.4 \%)$ \\
\hline
\end{tabular}

Demographics and clinical characteristics abstracted on the first unresected stage III NSCLC diagnosis

$A L K$ anaplastic lymphoma kinase, BMI body mass index, EGFR epidermal growth factor receptor, KRAS Kirsten rat sarcoma viral oncogene homolog, $N S C L C$ non-small cell lung cancer, $P D-1$ programmed cell death-1, $P D$ - $L 1$ programmed death-ligand-1, $S D$ standard deviation

10.0\%, ALK: 2.8\%, KRAS: 22.1\%, PD1: 52.2\%, PD-L1: $24.4 \%$.

The majority of patients were evenly divided between squamous cell carcinoma $(47.5 \%)$ and adenocarcinoma $(42.5 \%)$, with the remaining $10.0 \%$ of patients having other histology. The proportion of patients who were male was significantly higher in the Squamous Cell Carcinoma group than the Adenocarcinoma group (63.0\% vs. $46.3 \%$; $p<0.001)$. The proportion of patients who were Caucasian was significantly higher in the Squamous Cell Carcinoma group than the Adenocarcinoma group (78.9\% vs. $67.0 \%$; $p=0.006)$.

Separately, the sample was stratified according to stage III diagnosis (stage IIIA: $52.1 \%$, stage IIIB: $38.9 \%$, and stage III not specified: $9.0 \%$ ). Differences in patient characteristics between the stage IIIA group and stage IIIB group 
were nonsignificant, with one exception. The proportion of patients who progressed during the observation period to develop contralateral lung metastasis was significantly lower in the stage IIIA group compared to the stage IIIB group (7.6\% vs. $14.0 \% ; p=0.038)$.

Overall, 91.6\% (438/478) of patients received anti-cancer treatment in the first progression interval (Fig. 2). Over three quarters $(77.6 \%)$ of patients who were treated in the first progression interval received concurrent CRT (cCRT). A subgroup of patients progressed to the second (58.1\%) and third (27.4\%) progression intervals. The most common treatment in the second and third progression intervals was chemotherapy without radiation therapy, received by $55.4 \%$ $(112 / 202)$ and $70.1 \%$ (68/97) of treated patients, respectively. Complete data regarding treatment patterns for this sample are published elsewhere [20].

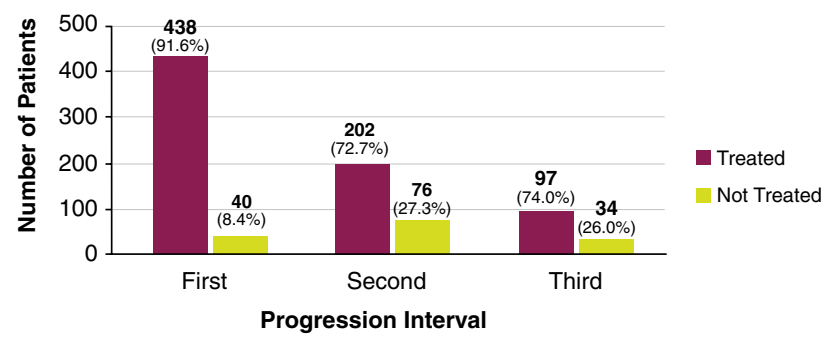

Fig. 2 Treatment receipt by progression interval

\section{Progression-free survival}

Median PFS from the index date to the date of the first disease progression was 10.0 months, with $83.5 \%$ (399/478) of patients experiencing an event (progression or death) during the study period. Median PFS was nominally longer in the stage IIIA group (10.6 months) compared to the stage IIIB group (8.4 months), but the difference was not statistically significant ( $p=0.151)$ (Fig. 3). There was no difference in PFS between the Adenocarcinoma and Squamous Cell Carcinoma groups (10.3 months vs. 10.6 months, respectively; $p=0.525$ ). Multivariate Cox regression analysis of PFS, controlling for stage, histology, and other patient characteristics, showed that patients with impaired performance status were 2.6 times more likely to have a PFS event than patients who were not impaired (HR 2.59, $p<0.001$ ). No other covariates in the analysis were statistically significant.

For the second progression interval $(n=278)$, median PFS was 4.2 months, and did not significantly differ across stage-based groups (stage IIIA: 4.9 months, stage IIIB: 3.8 months, $p=0.145$ ) or histology-based groups (Adenocarcinoma: 4.9 months vs. Squamous Cell Carcinoma: 3.6 months, $p=0.105$ ). Multivariate Cox regression analysis failed to identify any significant predictors of PFS in the second progression interval.

For the third progression interval $(n=130)$, median PFS was 3.1 months and differed between the stage IIIA and stage IIIB groups (stage IIIA: 3.3 months, stage IIIB: 2.9 months, $p=0.012$ ). However, PFS did not differ between the Adenocarcinoma and Squamous Cell Carcinoma groups (Adenocarcinoma: 3.0 months, Squamous Cell Carcinoma:
Fig. 3 Progression-free survival from stage III NSCLC diagnosis by stage-based group. *Log rank test between stage IIIA and stage IIIB groups. $C I$ confidence interval

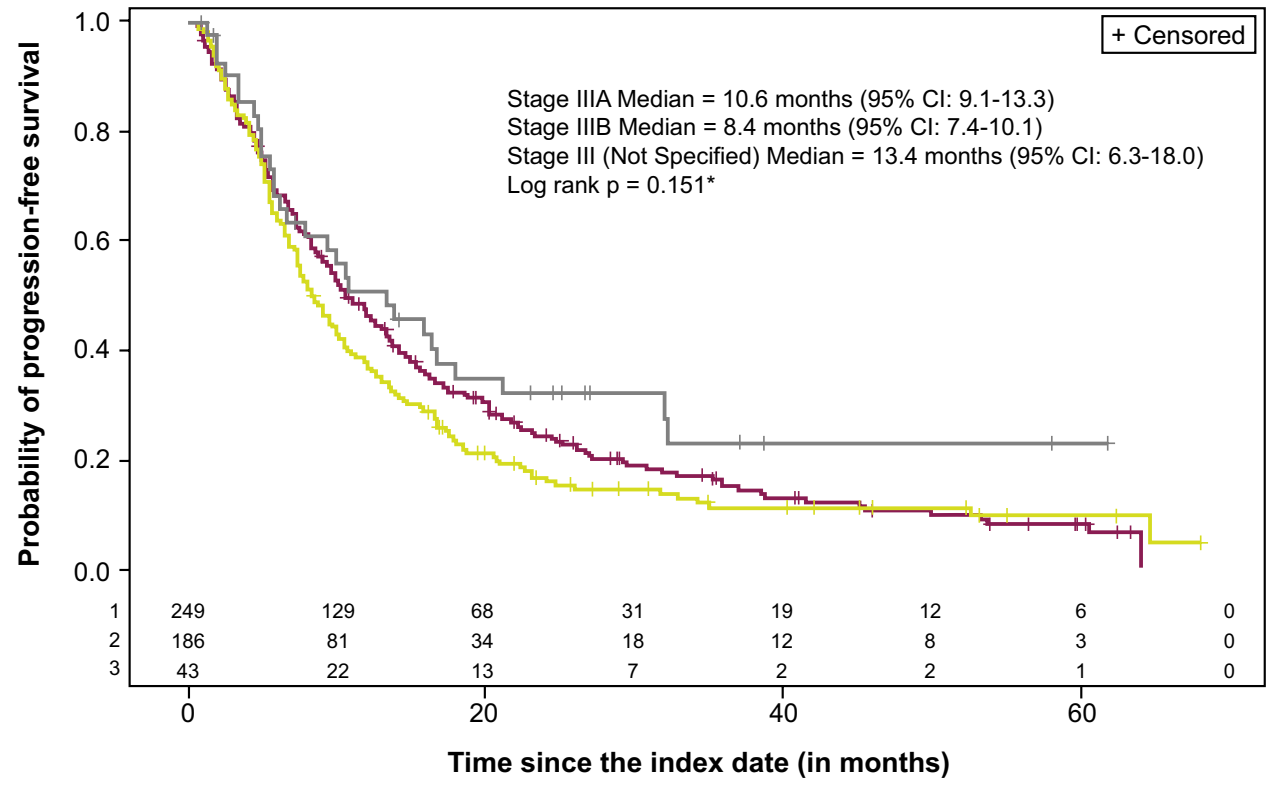

Group $\longrightarrow$ 1: Stage IIIA $\longrightarrow$ 2: Stage IIIB $\longrightarrow$ Stage III (not specified) 
3.2 months, $p=0.254)$. The multivariate Cox regression analysis of PFS identified receipt of radiation therapy as a significant predictor of PFS. Patients who received radiation therapy during this progression interval were less likely to experience an event (HR 0.50, $p=0.016$ ). No other covariates in the analysis were statistically significant.

\section{Overall survival}

Overall, 68.6\% (328/478) of patients died prior to the end of the observation period. Median OS was 19.5 months (95\% CI 17.0-22.0). Median values suggest slightly longer OS in the stage IIIA group (22.3 months) compared to the stage IIIB group (14.7 months), but the difference was not statistically significant $(p=0.148)$ (Fig. 4). There was no difference in OS between the Adenocarcinoma and Squamous Cell Carcinoma groups (Adenocarcinoma: 20.9 months vs. Squamous Cell Carcinoma: 18.9, $p=0.244$ ). In the multivariate Cox regression analysis of OS, after controlling for other factors, the stage IIIA group had a lower risk of death than the stage IIIB group (HR 0.77 [95\% CI 0.60-1.00], $p=0.045$ ). Patients who had received any radiation therapy in the first line also had lower risk (HR 0.71 [95\% CI 0.50-0.99], $p=0.042$ ). In contrast, patients with impaired performance status were 2.3 times as likely to die as those without impairment $(p<0.001)$. None of the other evaluated characteristics proved to be significant predictors of mortality.

\section{Time to metastasis}

During the study period, 181 of 478 patients (37.9\%) were diagnosed with metastatic disease. Patients who died prior to metastatic diagnosis were censored. Median TTM from stage III diagnosis for these 181 patients was 30.4 months overall (95\% CI 23.0-45.4), with the stage IIIA group having a significantly longer TTM ( $n=84,53.6$ months) than the stage IIIB group $(n=84,18.5$ months, $p=0.002)$. The Squamous Cell Carcinoma group had significantly longer $\operatorname{TTM}(\mathrm{n}=70,52.5$ months) than the Adenocarcinoma group ( $n=89,20.3$ months, $p=0.019$ ). The multivariate Cox regression analysis showed that the stage IIIA group had a lower risk of having a metastatic diagnosis than the stage IIIB group (HR 0.60 [95\% CI 0.43-0.84], $p=0.003$ ), but histology was not a significant predictor $(p=0.301)$.

\section{Symptom burden and quality of life}

PCM data were available for a subset of 167 patients. Observations were available for each patient on an average of seven separate occasions during the normal course of patient care. For all six Index Scores there was a significant increase (worsening) in the scores at occurrence of the first disease progression (General Physical Symptoms, Treatment Side Effects, Despair, and Impaired Ambulation: $p$ 's $<0.001$; Acute Distress: $p=0.044$ ). The same pattern of significant worsening of symptoms following the first disease progression was observed for the following symptoms: pain, difficulty breathing, and fatigue ( $p$ 's $<0.001)$. However, the pattern of severity for Index scores varied when separately
Fig. 4 Overall survival from stage III NSCLC diagnosis by stage-based group. *Log rank test between stage IIIA and stage IIIB groups. $C I$ confidence interval

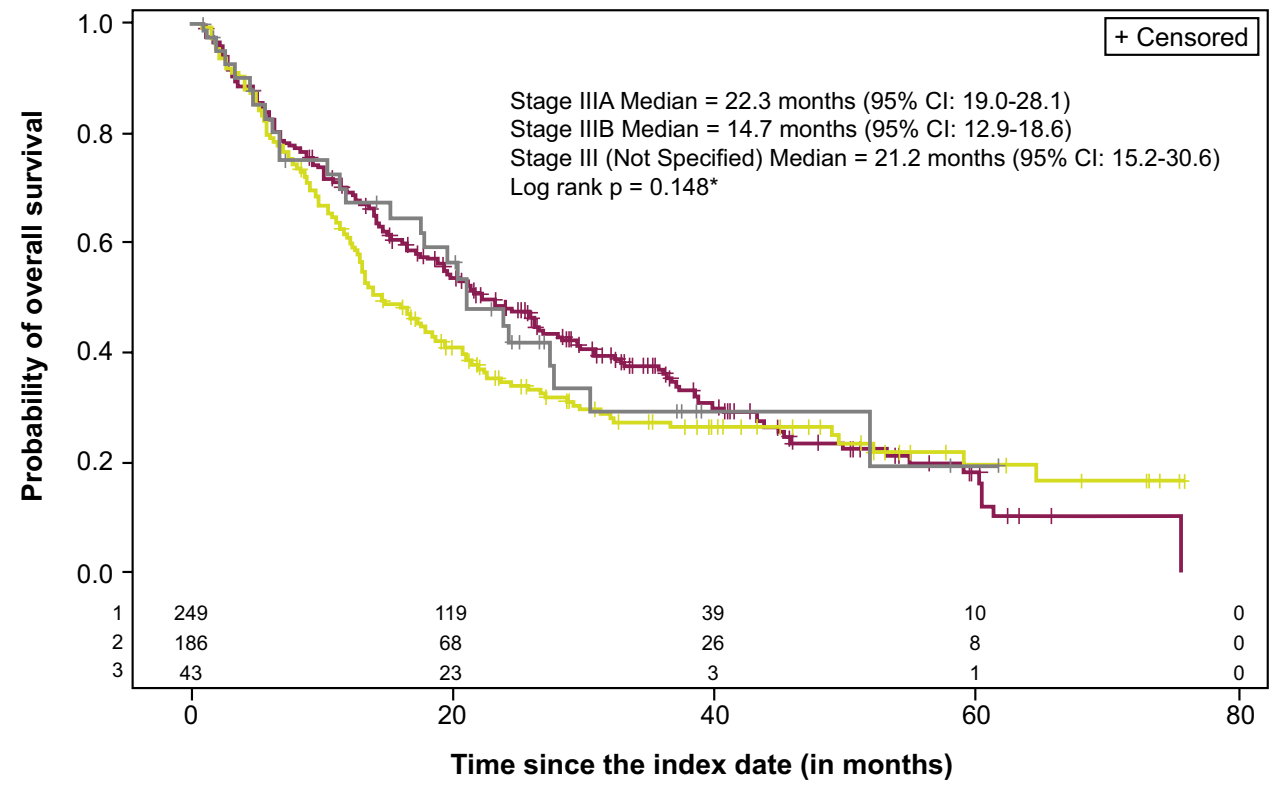

Group - 1: Stage IIIA $\longrightarrow$ 2: Stage IIIB $=$ Stage III (not specified) 
evaluated in the pre-progression period and the post-progression period. Of note, three index scores (Treatment Side Effects, Acute Distress, and Despair) showed improvement during the pre-progression period, but worsened post-progression at a magnitude that exceeded the improvement in the pre-progression period. The multivariate LMMs showed that receipt of radiation therapy and increasing age were associated with better overall HRQOL, whereas greater comorbidity burden and impaired performance status were associated with worse HRQOL.

\section{Discussion}

This retrospective, observational study investigated the clinical outcomes in unresected stage III NSCLC patients treated in a real-world community oncology setting prior to the approval of durvalumab. This study documented significant unmet medical need with median PFS of 10.0 months from the diagnosis of stage III NSCLC, and median OS of 19.5 months. This study also demonstrated that PFS was substantially shorter in progression intervals two and three (4 and 3 months, respectively) underscoring the poor prognosis for patients with progressive NSCLC. The majority of patients were treated with standard of care cCRT [21]; despite the curative intent of cCRT, the OS outcome of less than 20 months in this study highlighted the need for improved treatment options in the stage III NSCLC setting.

The OS results from this study are in-line with a published meta-analysis [22] and other recent population-based studies of patients diagnosed with unresected stage III NSCLC who received cCRT (median OS 13 to 18 months) [23-25], but are shorter than results for the standard radiation dose arm (29 months) in the recently completed Radiation Therapy Oncology Group (RTOG) clinical trial that evaluated optimal cCRT regimens (RTOG 0617) [26]. The current study did not assess radiation dose, and included patients not treated with radiation, or treated with radiation therapy only, all of which may explain discrepancies in findings between our study and RTOG 0617.

This analysis showed little or no effect of histology, and only modest effects of stage III subtypes on PFS and OS. However, patients diagnosed with stage IIIB disease appeared to have a worse prognosis compared to patients diagnosed with stage IIIA disease. Patients with stage IIIB disease had shorter time to diagnosis of metastatic disease in the univariate Kaplan-Meier analysis and higher risk of metastatic diagnosis than patients with stage IIIA disease in the multivariate analysis.

In addition to clinical outcomes, this study analyzed HRQOL data collected as part of routine clinical practice. This study documented a consistent pattern of decline in HRQOL at disease progression. Disease progression was not only associated with physical symptom worsening, but also with negative psychological states such as distress and despair. The pattern of decline in HRQOL following disease progression has been observed in other tumor types, such as breast cancer, where the same measure was used [15]. With over half of all patients in this study (58.2\%) experiencing at least one disease progression event, the implications of this finding are noteworthy. Clinicians should expect significant deterioration of patient quality of life following disease progression and prepare for a proactive approach to symptom management to prevent long-term consequences. Prior research also has shown that integration of patient-reported outcomes into routine oncology care is associated with better clinical outcomes, such as survival [27]. Future research could explore whether a similar impact is seen with the use of the PCM 2.0.

This research adds to the broader understanding of unresected stage III NSCLC by highlighting the unmet need that existed in this setting. Although a large majority of patients received CRT, not all did, and most patients eventually progressed to later lines in the locoregional or metastatic setting. These findings also suggest that locoregional progression can lead to death without evidence of metastatic disease, or that metastatic disease may go undiagnosed in some patients.

To our knowledge, this is the first study to look at realworld outcomes in unresected stage III NSCLC patients treated in a community oncology setting. These findings clearly indicate that there has been room for improvement in the treatment of these patients. In addition to the recently approved durvalumab [10], there are several active clinical trials involving the use of both radiotherapy and immunotherapy such as cancer vaccines, cytotoxic T-lymphocyteassociated antigen-4 (CTLA-4) inhibitors, PD-1 inhibitors, and PD-L1 inhibitors in unresectable stage III NSCLC patients [28]. Further research is warranted to evaluate the impact of these new therapies on real-world patient outcomes once they are approved and widely available.

\section{Limitations}

The Vector Oncology Data Warehouse is limited to patients treated in the community oncology setting, with the majority of patients residing in the Southern region of the United States. The results of this study may not be representative of patients treated in other settings such as research and academic centers, or those in other regions of the United States. Additionally, the information included in the Vector Oncology Data Warehouse was not collected for research purposes; therefore, the study analyses are limited to data available within the existing EMR. PCM data were available for a minority subset of patients, which limited the complexity of the models $(n=167)$. The effects associated with 
disease progression were large, however, and it is unlikely that a larger sample size would have resulted in different effects than those observed. Even so, a larger sample size would have been better for estimating the magnitude of effects associated with disease progression. The study examined TTM as an endpoint, but did not examine time to death or distant metastasis, a composite endpoint examined in other recent research [29], and potentially relevant given that more patients died during the study period than were reported as metastatic. Finally, the study period preceded the approval of newer therapies (e.g., PD-1 and PD-L1 agents, newer tyrosine kinase inhibitors) which may significantly influence treatment practice patterns and survival outcomes in patients who have progressed from stage III to stage IV NSCLC. Unfortunately, the time frame of this study did not permit adequate representations of these changes and the potential impact on OS.

\section{Conclusion}

This study documented real-world PFS and OS consistent with the published literature and highlighted the need for better therapeutic options for patients with unresected stage III NSCLC. The majority of patients experienced disease progression, and two-thirds of patients died during the study period. The broader implication of disease progression was the association with worsening quality of life, particularly for physical symptoms and psychological states. Future studies should examine the impact of newer treatment options on the evolution of real-world treatment patterns and clinical outcomes.

Data availability Vector Oncology does not make datasets publicly available because study data are used under license from source practices. Vector Oncology will consider requests to access study datasets on a case-by-case basis

\section{Compliance with ethical standards}

Conflict of interest KJR, AWF, and MP are employed by AstraZeneca and own stock in AstraZeneca. KES and MSW are employed by Vector Oncology. RSP was employed by Vector Oncology during the conduct of the research. NAV reports no conflicts of interest. AstraZeneca sponsored this study and provided financial support for the conduct of the research and for preparation of the article. The sponsor collaborated on the design of the study, interpretation of the analyses, and in the decision to submit the article for publication. The sponsor did not have a direct role in data collection, data analysis, or writing of the report.

Ethical approval This study was approved by IntegReview institutional review board (Austin, TX) and has been performed in accordance with the ethical standards as laid down in the 1964 Declaration of Helsinki and its later amendments or comparable ethical standards. This study involved retrospective analysis of existing data with no patient intervention or interaction.
Open Access This article is distributed under the terms of the Creative Commons Attribution 4.0 International License (http://creativeco mmons.org/licenses/by/4.0/), which permits unrestricted use, distribution, and reproduction in any medium, provided you give appropriate credit to the original author(s) and the source, provide a link to the Creative Commons license, and indicate if changes were made.

\section{References}

1. Siegel RL, Miller KD, Jemal A. Cancer statistics. CA Cancer J Clin. 2018. https://doi.org/10.3322/caac.21387. 2018.

2. Ries LAG, Eisner MP, Kosary CL, Hankey BF, Miller BA, Clegg L, et al. SEER cancer statistics review, 1973-1999. Bethesda, MD: National Cancer Institute; 2002.

3. National Comprehensive Cancer Network (NCCN). NCCN clinical practice guidelines in oncology: non-small cell lung cancer. 2018.

4. Goldstraw P, Chansky K, Crowley J, Rami-Porta R, Asamura H, Eberhardt WE, et al. The IASLC Lung Cancer Staging Project: proposals for revision of the TNM stage groupings in the forthcoming (eighth) edition of the TNM classification for lung cancer. J Thorac Oncol. 2016;11(1):39-51. https://doi.org/10.1016/j. jtho.2015.09.009.

5. Kay FU, Kandathil A, Batra K, Saboo SS, Abbara S, Rajiah P. Revisions to the tumor, node, metastasis staging of lung cancer (8(th) edition): rationale, radiologic findings and clinical implications. World J Radiol. 2017;9(6):269-79. https://doi.org/10.4329/ wjr.v9.i6.269.

6. Rami-Porta R, Asamura H, Travis WD, Rusch VW. Lung cancer - major changes in the American Joint Committee on Cancer eighth edition cancer staging manual. CA Cancer J Clin. 2017;67(2):138-55. https://doi.org/10.3322/caac.21390.

7. Bezjak A, Temin S, Franklin G, Giaccone G, Govindan R, Johnson ML, et al. Definitive and adjuvant radiotherapy in locally advanced non-small-cell lung cancer: American Society of Clinical Oncology Clinical Practice Guideline endorsement of the American Society for Radiation Oncology Evidence-Based Clinical Practice Guideline. J Clin Oncol. 2015;33(18):2100-5. https://doi.org/10.1200/JCO.2014.59.2360.

8. Vansteenkiste J, De Ruysscher D, Eberhardt WE, Lim E, Senan S, Felip E, et al. Early and locally advanced non-small-cell lung cancer (NSCLC): ESMO clinical practice guidelines for diagnosis, treatment and follow-up. Ann Oncol. 2013;24(Suppl 6):vi89-98. https://doi.org/10.1093/annonc/mdt241.

9. Dillman RO, Herndon J, Seagren SL, Eaton WL Jr, Green MR. Improved survival in stage III non-small-cell lung cancer: sevenyear follow-up of cancer and leukemia group B (CALGB) 8433 trial. J Natl Cancer Inst. 1996;88(17):1210-5.

10. Imfinzi. (durvalumab) Injection [prescribing information]. Wilmington: AstraZeneca Pharmaceuticals LP; 2018.

11. Abernethy AP, Zafar SY, Uronis H, Wheeler JL, Coan A, Rowe $\mathrm{K}$, et al. Validation of the Patient Care Monitor (Version 2.0): a review of system assessment instrument for cancer patients. J Pain Symptom Manage. 2010;40(4):545-58. https://doi.org/10.1016/j. jpainsymman.2010.01.017.

12. Houts AC, Lipinski D, Olsen JP, Baldwin S, Hasan M. Use of the Patient Care Monitor to screen for depression in adult cancer patients interviewed with the structured clinical interview for DSM-IV. Psycho-Oncology. 2010;19(4):399-407. https://doi. org/10.1002/pon.1583.

13. Stepanski EJ, Walker MS, Schwartzberg LS, Blakely LJ, Ong JC, Houts AC. The relation of trouble sleeping, depressed mood, pain, and fatigue in patients with cancer. J Clin Sleep Med. 2009;5(2):132-6. 
14. Schwartzberg LS, Cobb P, Walker MS, Stepanski EJ, Houts AC. Patient and practice impact of capecitabine compared to taxanes in first-/second-line chemotherapy for metastatic breast cancer. Support Care Cancer. 2009;17(8):1081-8. https://doi.org/10.1007/ s00520-008-0558-2.

15. Walker MS, Hasan M, Yim YM, Yu E, Stepanski EJ, Schwartzberg LS. Retrospective study of the effect of disease progression on patient reported outcomes in HER-2 negative metastatic breast cancer patients. Health Qual Life Outcomes. 2011;9:46. https:// doi.org/10.1186/1477-7525-9-46.

16. Walker MS, Masaquel AS, Kerr J, Lalla D, Abidoye O, Houts AC, et al. Early treatment discontinuation and switching in first-line metastatic breast cancer: the role of patient-reported symptom burden. Breast Cancer Res Treat. 2014;144(3):673-81. https:// doi.org/10.1007/s10549-014-2892-z.

17. Walker MS, Schwartzberg LS, Stepanski EJ, Fortner BV. A retrospective study of quality of life in a community sample of patients with early stage breast cancer. Breast Cancer Res Treat. 2009;115(2):415-22. https://doi.org/10.1007/s10549-009-0387-0.

18. Fortner B, Baldwin S, Schwartzberg L, Houts AC. Validation of the Cancer Care Monitor items for physical symptoms and treatment side effects using expert oncology nurse evaluation. J Pain Symptom Manage. 2006;31(3):207-14. https://doi.org/10.1016/j. jpainsymman.2005.07.009.

19. Fortner B, Okon T, Schwartzberg L, Tauer K, Houts AC. The Cancer Care Monitor: psychometric content evaluation and pilot testing of a computer administered system for symptom screening and quality of life in adult cancer patients. J Pain Symptom Manage. 2003;26(6):1077-92.

20. Ryan KJ, Skinner KE, Fernandes AW, Punekar RS, Pavilack M, Walker MS, et al. Real-world treatment patterns among patients with unresected stage III non-small cell lung cancer (NSCLC). Manuscript in development. 2018.

21. Curran WJ Jr, Paulus R, Langer CJ, Komaki R, Lee JS, Hauser S, et al. Sequential vs. concurrent chemoradiation for stage III nonsmall cell lung cancer: randomized phase III trial RTOG 9410. J Natl Cancer Inst. 2011;103(19):1452-60. https://doi.org/10.1093/ jnci/djr325.

22. Auperin A, Le Pechoux C, Rolland E, Curran WJ, Furuse K, Fournel $\mathrm{P}$, et al. Meta-analysis of concomitant versus sequential radiochemotherapy in locally advanced non-small-cell lung cancer.
J Clin Oncol. 2010;28(13):2181-90. https://doi.org/10.1200/ JCO.2009.26.2543.

23. Davidoff AJ, Gardner JF, Seal B, Edelman MJ. Population-based estimates of survival benefit associated with combined modality therapy in elderly patients with locally advanced non-small cell lung cancer. J Thorac Oncol. 2011;6(5):934-41. https://doi. org/10.1097/JTO.0b013e31820eed00.

24. Ezer N, Smith CB, Galsky MD, Mhango G, Gu F, Gomez J, et al. Cisplatin vs. carboplatin-based chemoradiotherapy in patients $>$ 65 years of age with stage III non-small cell lung cancer. Radiother Oncol. 2014;112(2):272-8. https://doi.org/10.1016/j.radon c.2014.07.014.

25. Miller ED, Fisher JL, Haglund KE, Grecula JC, Xu-Welliver M, Bertino EM, et al. The addition of chemotherapy to radiation therapy improves survival in elderly patients with stage III non-small cell lung cancer. J Thorac Oncol. 2018;13(3):426-35. https://doi. org/10.1016/j.jtho.2017.11.135.

26. Bradley JD, Paulus R, Komaki R, Masters G, Blumenschein G, Schild $\mathrm{S}$, et al. Standard-dose versus high-dose conformal radiotherapy with concurrent and consolidation carboplatin plus paclitaxel with or without cetuximab for patients with stage IIIA or IIIB non-small-cell lung cancer (RTOG 0617): a randomised, twoby-two factorial phase 3 study. Lancet Oncol. 2015;16(2):187-99. https://doi.org/10.1016/S1470-2045(14)71207-0.

27. Basch E, Deal AM, Dueck AC, Scher HI, Kris MG, Hudis C, et al. Overall survival results of a trial assessing patient-reported outcomes for symptom monitoring during routine cancer treatment. Jama. 2017;318(2):197-8. https://doi.org/10.1001/ jama.2017.7156.

28. ClinicalTrials.gov [database on the Internet]2018. Available from: https://clinicaltrials.gov/. Accessed: September 11, 2018.

29. Antonia SJ, Villegas A, Daniel D, Vicente D, Murakami S, Hui R, et al. Durvalumab after chemoradiotherapy in stage III non-smallcell lung cancer. N Engl J Med. 2017;377(20):1919-29. https:// doi.org/10.1056/NEJMoa1709937.

Publisher's Note Springer Nature remains neutral with regard to jurisdictional claims in published maps and institutional affiliations. 